\title{
VERGÊNCIA CENTRÍFUGA RESIDUAL NO SISTEMA DE DOBRAMENTOS SERGIPANO
}

\author{
BENJAMIM BLEY DE BRITO NEVES*, ALGIDES NÓBREGA SIAL* $\mathrm{e}$ \\ JOSE DO PATROGINIO TOMAZ ALBUQUERQUE**
}

\begin{abstract}
The Sergipean fold system, with a maximum width of $200 \mathrm{~km}$, total lenght of $400 \mathrm{~km}$, general NW-SE trend, total area of $45000 \mathrm{~km}^{2}$, triangle-shaped, is located in the states of Sergipe, Alagoas and Bahia. Field relationships suggest bilateral symmetry for the whole system, with two fold belts, separated by an axial zone characterized by a number of calcalkaline intrusions and several exposures of the basement. The northern fold belt, south Alagoas, exhibits a psamitic-pelitic meta-sedimentary sequence partially migmatised, subordinate limestone, some magmatism, metamorphism of amphibolite facies predominating over greenschist one, and axial planes of folds with vergence towards the Pernambuco-Alagoas massif, to the north (eugeosynclinal development). In the southern fold belt, in Sergipe, a carbonatic-pelitic miogeosynclinal sequence predominates. The metamorphism is of low-rank, greenschist facies, and folds show axial planes with vergence towards the São Francisco craton, to the south. A preliminary plate tectonic model for the evolution of the whole folding system, involving collision of two rigid plates (the Pernambuco-Alagoas massif and the São Francisco craton) is discussed.
\end{abstract}

INTRODUÇÃo O "Sistema de Dobramentos Sergipano", na concepção formulada aqui, estende-se das costas dos estados de Sergipe e Alagoas, onde alcança uma largura da ordem de $200 \mathrm{~km}$, até ao sul da cidade de Curaçá, ao norte do Estado da Bahia. O eixo desse sistema, que exibe uma forma aproximadamente triangular, dispõe-se na direção WNW-ESE em sua porção oriental, assumindo direção NW-SE em sua porção ocidental, no Estado da Bahia. Apresenta cerca de $400 \mathrm{~km}$ lineares, de forma que o sistema em conjunto perfaz uma área de quase $45000 \mathrm{~km}^{2}$. No cenário geotectônico regional, esse sistema acha-se situado a nordeste do Cráton do São Francisco, entre este e o. Maciço Pernambuco-Alagoas.

A designação proposta, no presente trabalho, procura substituir e ampliar as designações anteriores de "Geossinclinal de Sergipe" ou "de Propriá", devidas respectivamente a Humphrey e Allard (1969) e Allard (1969). A concepção de sistemas de dobramentos (Khain e Sheymann, 1962) é aplicada à unidade em epígrafe, uma vez que um nítido zoneamento geotectônico foi observado na mesma. Esse zoneamento se constitui em duas áreas lineares de dobramentos (faixas), distintas ao curso de toda a sua evolução geológica, a partir da instalação do processo de desenvolvimento.

A partir disso, propõe-se um desenvolvimento geossinclinal composto por dois sulcos de diferente natureza, separados por uma zona axial de divergência, de característica geoanticlinal:

Neste trabalho, constitui a principal preocupação dos autores a caracterização dos diferentes segmentos dessa unidade geotectônica tanto dentro dos moldes clássicos de desenvolvimento geossinclinal, como a partir de choque de placas litosféricas, segundo os modernos conceitos da Teoria das Placas.

*Departamento de Geologia, Gentro de Tecnologia, UFPE, Recife

**Departamento de Geociências, Centro de Ciências e Tecnologia, UFPB, Campina Grande 
Subsídios de diversos mapeamentos geológicos na área em apreço, estudos posteriores aos trabalhos pioneiros mencionados e observações diretas de campo constituíram as fontes de informações utilizadas. Um estudo progressivo de mapeamento e um conhecimento detalhado do Sistema de Dobramentos Sergipano é parte do programa de pesquisas dos autores e do treinamento de estudantes de Geologia da Universidade Federal de Pernambuco.

Os trabalhos de Sobral (1964), Farina (1966), Kegel e Barroso (1966), Barbosa (1970), Leite (1969), Jordan (1971), Brito Neves (1975), Santos e Silva Filho (1975), entre outros, merecem destaque pela efetiva contribuição na evolução dos conhecimentos geológicos regionais. As folhas do Inventário Hidrogeológico Básico do Nordeste (folhas 19, 20, 24 e 25, de 1970/1971) resumem parte dos diferentes trabalhos desenvolvidos nessa unidade geotectônica e constituíram excelente apoio ao esquema regional apresentado.

o Sistema de Dobramentos Sergipano ANÁLISE GEOTEGTÔNIGA REGIONAL O acervo de dados existentes sobre o Sistema de Dobramentos Sergipano junto aos levantamentos encetados pelos autores permitem uma integralização dos conhecimentos e a proposição de uma regionalização geotectônica (Figs. 1 e 2).

Convém ressaltar a simetria bilateral do sistema de dobramentos, estabelecida pela zona geoanticlinal proposta por Brito Neves (1975), consubstanciando faixas paralelas de diferentes conotações geológicas e geotectônicas. Essa zona geoanticlinal se dispõe ao longo do paralelo de Propriá, no baixo São Francisco, desde Igreja Nova, a leste de Sergipe, até, pelo menos, Jeremoabo, a oeste, na Bahia. Projeta-se no embasamento da Bacia do Tucano, com continuidade obscurecida no segmento norte-ocidental do sistema de dobramentos, na Bahia, e que será caracterizado a seguir.

O Cráton do São Francisco, ao sul (Almeida, 1967), e o Maciço Pernambuco-Alagoas, ao norte (Brito Neves e Cordani, 1973), funcionaram respectivamente como antepaís e além-país do desenvolvimento. A zona dobrada, ao sul da zona geoanticlinal (Sergipana), apresenta características típicas que podem ser enquadradas na conotação clássica dos desenvolvimentos miogeossinclinais, em termos de sedimentação, magmatismo, metamorfismo, ou mais precisamente, dos sulcos calcários (limestone trough) do primeiro tipo, de Muratov (em Khain e Sheynmann, 1962), sendo caracterizada por uma mobilidade moderada. A zona dobrada, ao norte da zona geoanticlinal (zona ou faixa Sul Alagoana), é produto da evolução de um desenvolvimento mais complexo de sítios de sedimentação instáveis, com participação de processos de dobramento, magmatismo e metamorfismo mais variados, aproximando-se da evolução preconizada para os domínios eugeossinclinais, ou mais precisamente das "zonas terrígenas" (Zonenshayn, 1967), ou ainda de sulcos do tipo "flysch" ou "slate" de Muratov (op. cit.), que se referem a um grau elevado de mobilidade.

Sobre o núcleo cratônico do São Francisco, ao sul, são reconhecidos depósitos pericratônicos preservados, representados por quartzitos, conglomerados, siltitos e calcários, moderadamente dobrados (Grupo Miaba, de Humphrey e Allard, 1969; Grupo Bambuí, de Barbosa, 1970), restos de extrapolação sobre a plataforma de depósitos miogeossinclinais, na fase de maior subsidència, nọ período de pré-inversão, da zona miogeossinclinal.

Sobre a plataforma, desenvolveu-se uma típica antefossa (antefossa de Lagarto-Tobias Barreto), contendo sedimentos continentais pós-tectônicos do Grupo Estância, cuja fonte foi constituída pelos metamorfitos da zona dobrada vizinha. Esses sedimentos acobertam grande extensão dos depósitos pericratônicos da plataforma (Carozzi et al, 1976; Allard e Tibana, 1966).

Sobre a zona geoanticlinal, na fossa de "Juá-Fazenda de Dentro", acumularam-se, igualmente, sedimentos pós-tectônicos, com presença de psefitos polimícticos ao lado de 


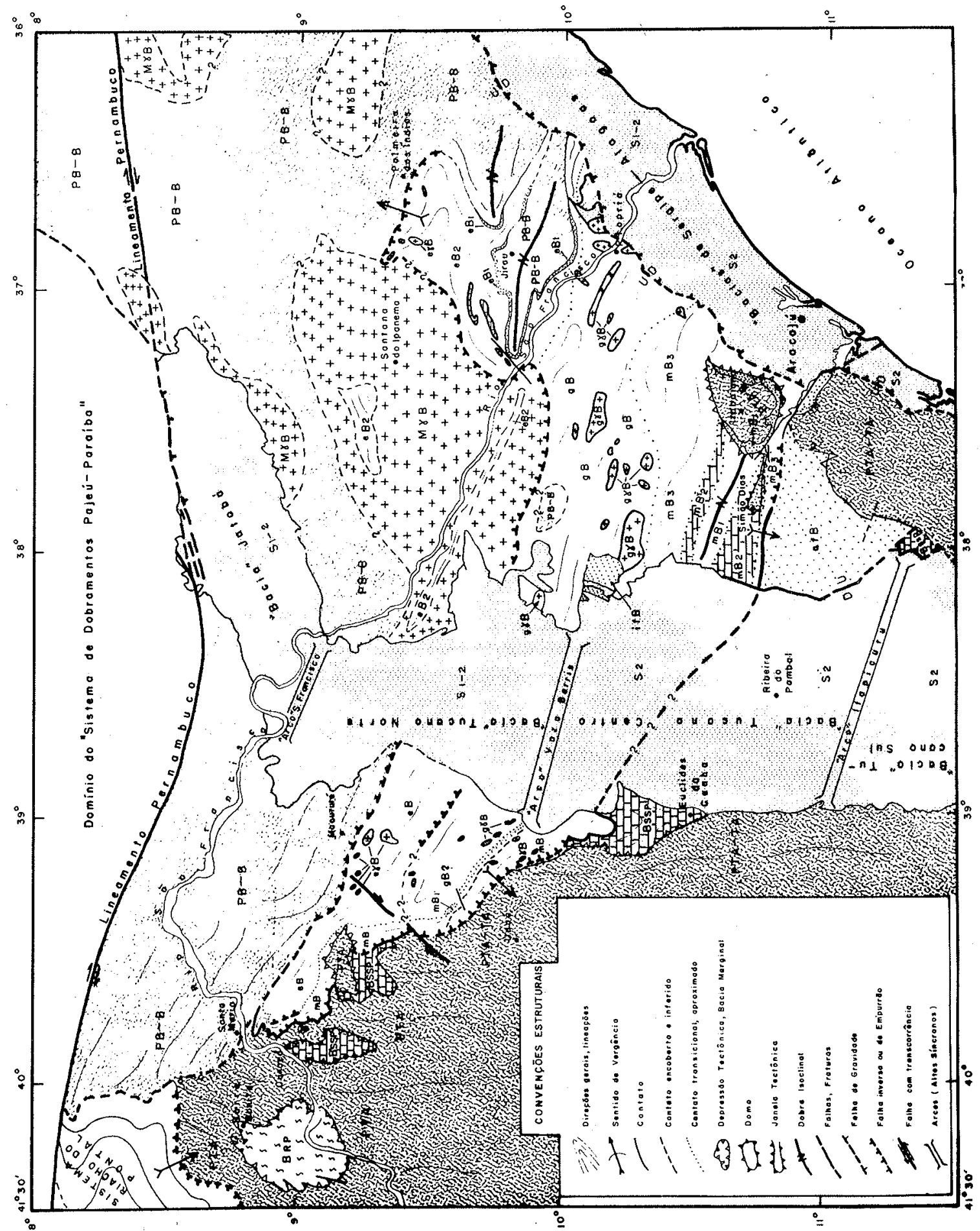




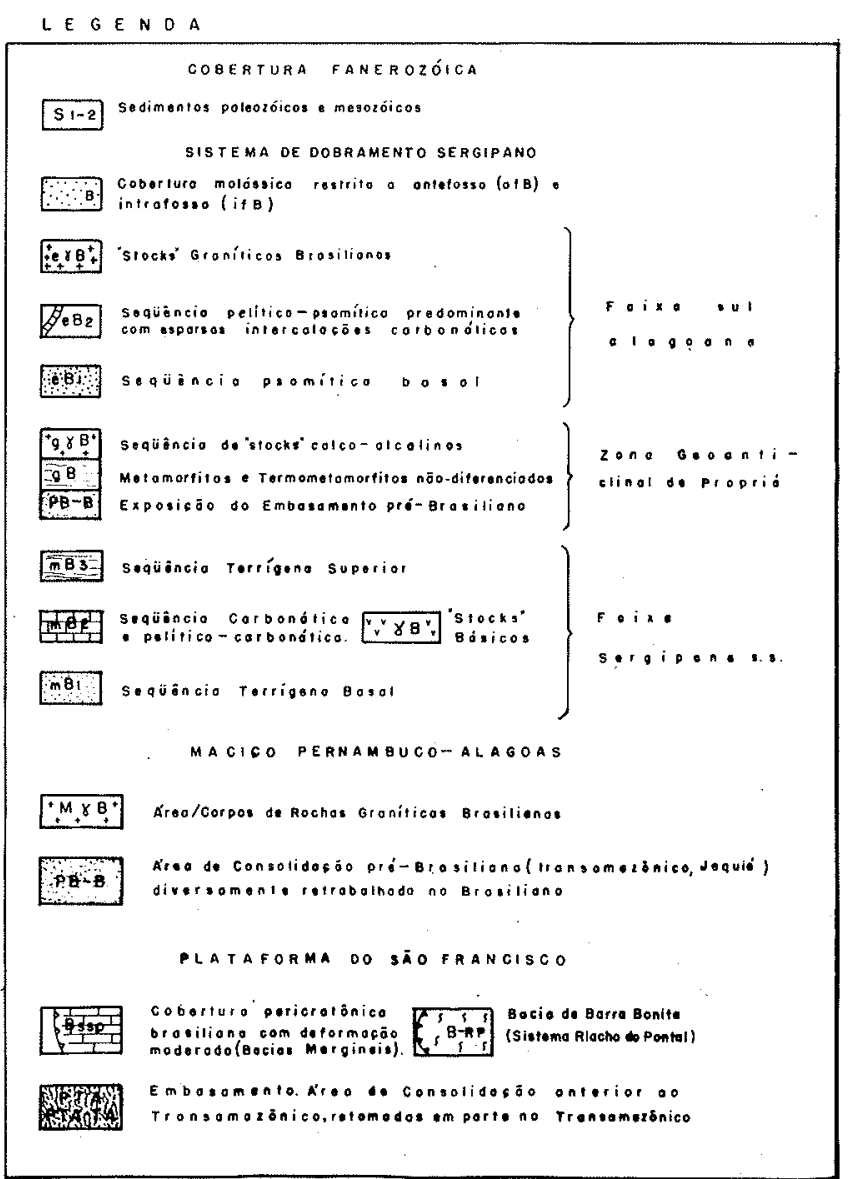

Figura 1 - Mapa geotectônico preliminar do Sistema de Dobramentos Sergipano (1976)

psamitos imaturos e coloridos, consubstanciando características de uma intrafossa (intradeep). Geralmente esses sedimentos mostram cor marrom-arroxeada, contêm fragmentos de filitos e quartzo esverdeado e localmente exibem estratificação cruzada.

Embora não se possa assegurar relações lito e cronoestratigráficas entre as sequeèncias depositadas nas zonas dobradas separadas pelo geoanticlinal de Propriá, o problema de migração/polaridade da sedimentação permanece em aberto. Do ponto de vista estrutural, é notória a divergência a partir da zona geoanticlinal, dirigindo-se centrifugamente para o núcleo cratônico, ao sul, e para o maciço mediano, ao norte, como produto da tectogênese primária dos dobramentos, a ser analisada. Sobrepõe-se a essa fase um importante episódio de deslocamentos e empurrões, todos eles dirigidos para o sul e sudeste, que afetam igualmente ambas as zonas. $\mathrm{Na}$ zona alagoana, essa tectônica tardia está associada e ressaltada pelo posicionamento e deslocamento de um imenso batólito, às margens do Maciço Pernambuco-Alagoas, o batólito de Santana do Ipanema-Monteirópolis. O posicionamento tardio (pós-dobramento, pós-metamorfismo regional) desse batólito está claramente assinalado na natureza e nas dimensões de seus xenólitos, bem como no deslocamento, e mesmo no redobramento, que impõe ao esquema primário de dobramentos E-W da zona Sul Alagoana. 


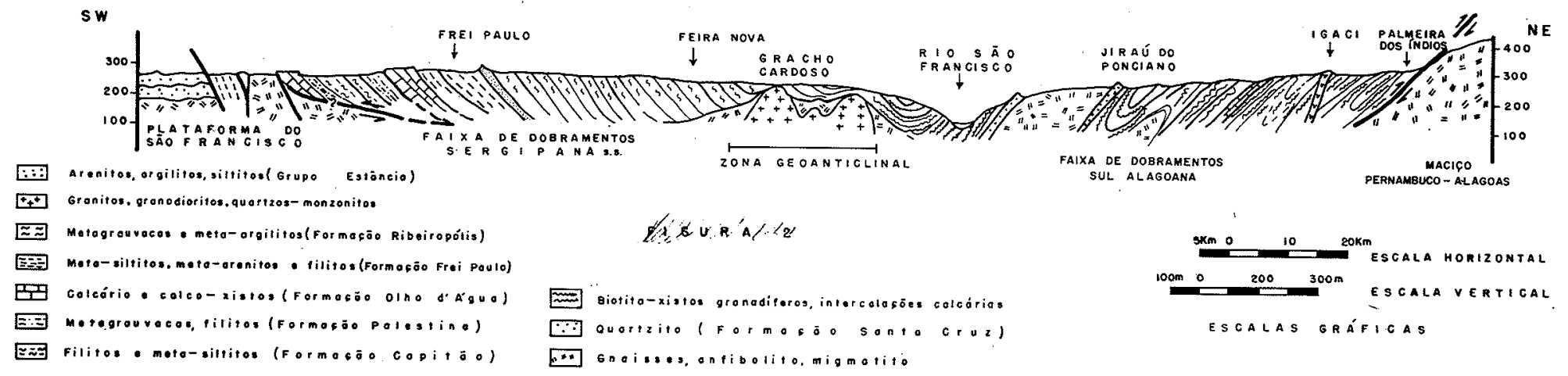

Figura 2 - Perfil geológico do Sistema de Dobramentos Sergipano, entre Palmeira dos Indios- Alagoas e Simão Dias-Sergipe 
No segmento norte ocidental do sistema (no norte da Bahia), a mecânica tardia de falhamentos inversos e de empurrões dirigidos para sul e sudeste chega a obscurecer o zoneamento geotectônico, fato salientado pelo adelgaçamento do sistema, que ali tem estreita largura de dobramento, bem como pela intensificação desse processo compressional. É válido acrescentar que esse sistema de dobramentos, neste ensejo discutido em separado, é parte da Região de Dobramentos Nordeste (Almeida et al., 1976), da qual constitui o sistema marginal sul, com referência a sua proximidade ao núcleo cratônico de São Francisco (Brito Neves, 1977, no prelo).

GONFRONTO DAS ZONAS LINEARES DE DOBRAMENTOS O Sistema de Dobramentos Sergipano, como concebido neste trabalho, compõe-se de duas zonas lineares de dobramentos (faixas), a Sul Alagoana e a Sergipana, separadas por uma zona axial de divergência intermediária, que mostram uma série de diferenças ao longo de sua evolução geológica, a partir da implantação geotectônica das mesmas.

a) A zona Sul Alagoana é produto da evolução e consolidação de um sulco geossinclinal implantado às bordas do Maciço Pernambuco-Alagoas, tendo sido caracterizada por 'uma sedimentação exógena e imatura, ou seja, do tipo terrígeno, proveniente da erosão de altos interiores e externos aos sítios deposicionais. $\mathrm{O}$ metamorfismo regional em fácies anfibolito produziu a formação de quartzitos, micaxistos, metarcózios, sendo os níveis calcários subordinados e esparsos.

A zona Sergipana é produto da evolução e consolidação de um sulco geossinclinal localizado às bordas do Cráton do São Francisco, sendo caracterizada por moderada instabilidade, com uma sedimentação pelítico-carbonática, por excelência, equivalente à própria cobertura da plataforma. Nessa zona há uma espessa, extensa e contínua unidade carbonática ("Olhos d'Água", "Jacoca"), intermediária às seções clásticas. O desenvolvimento desse sulco aproxima-se dos clássicos miogeossinclíneos.

b) O Quadro I sintetiza as colunas litoestratigráficas propostas na área, procurando ficar à margem das dissensões existentes e naturais, face ao estágio atual de conhecimentos.

c) A zona Sul Alagoana, quanto ao estilo de dobramento, é caracterizada por um dobramento contínuo, linear, com muitas dobras de fluxo e onde o embasamento teve uma participação marcante, estando exposto nos núcleos anticlinoriais, como em Arapiraca e Jirau do Ponciano. $\mathrm{O}$ fato de slickensides serem observados nos quartzitos Santa Cruz, quase-coincidentes com a direção de mergulho da xistosidade, sugere que essa fatia do embasamento ali exposta (no centro do anticlinório de Jirau) foi soerguida por falhamento de empurrão/inverso, associado à vergência geral para o norte de toda a zona Sul Alagoana. A culminação dessa vergência é a falha de empurrão/inversa de Palmeira dos Indios, jogando os metamorfitos dessa faixa sobre os migmatitos do Maciço Pernambuco-Alagoas (de sul para norte).

Modificações posteriores provocadas pelos empurrões são resultantes do cavalgamento do batólito de Santana de Ipanema (de norte para sul) sobre os metamorfitos da faixa Sul Alagoana, produzindo a formação de milonitos e cataclasitos e ainda dando início a redobramentos na direção primária E-W previamente estabelecida. A dupla xistosidade observada nos migmatitos da Fazenda Camarão (no anticlinório de Jirau) reproduz a superposição de duas distintas fases compressionais.

$\mathrm{Na}$ zona Sergipana, observa-se um dobramento fechado, linear, de direção WNW-ESE, e que se separa do embasamento sotoposto por uma "superfície de deslocamento" ("a falha de Macambira"). O embasamento acha-se exposto na janela tectônica de Simão Dias e no domo soerguido de Itabaiana.

As relações entre xistosidade e o acamadamento, bem como a própria inclinação 
QUADHO 1 - SÍNTESE DAS COLUNAS LTTOLSTRATIGRÁFCAS PROPOSTAS NU SISTEMA DE DOBRAMENTUS SLRGIPANO

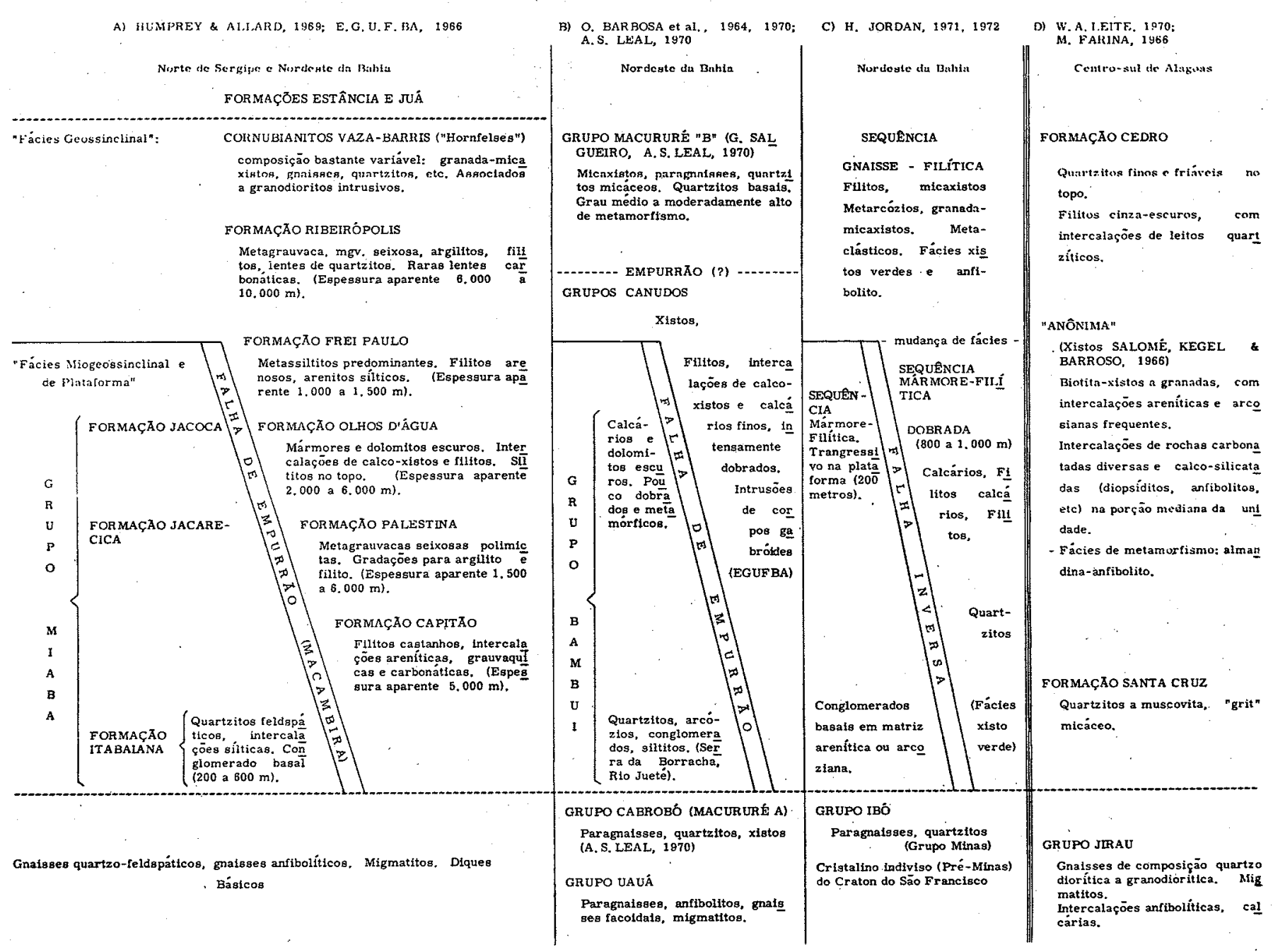


dos planos axiais de dobramento, mostram a vergência para o sul dessa faixa, no sentido do Cráton de São Francisco, crescendo essa tendência gradativamente a partir da zona geoanticlinal. As rochas do embasamento comportaram-se de forma competente a esse deslocamento dirigido para o sul, respondendo à compressão lateral com soerguimento de blocos (janela de Simão Dias, domo de Itabaiana).

Essa tendência de empurrões para o sul, da zona Sergipana, mostra recrudescimentos tardios, de forma que, em parte, os metassedimentos Vaza Barris mostram localmente contatos por falha de empurrão com os sedimentos molássicos do Grupo Estância, como observado entre Lagarto e São Domingos, em trecho do vale do Vaza Barris.

d) Na zona Sul Alagoana, o metamorfismo regional é de fácies anfibolito, pássando gradativamente, ao sul (imediações da zona geoanticlinal), para a fácies xisto verde. Observa-se migmatização relativamente bem distribuída nessa faixa; metamorfismo dinâmico é localmente observado junto às falhas e zonas redobradas, especialmente onde o embasamento teve participação efetiva.

Na zona Sergipana, foi observado um metamorfismo regional uniforme na fácies xisto verde, não se verificando fenômenos de migmatização.

Sobre a zona axial de divergência de Propriá, a temperatura desempenhou papel mais importante no metamorfismo, observando-se a formação de hornfelses nas auréolas de contato dos diversos stocks calco-alcalinos. Observa-se freqüentemente o aparecimento de granadas de dimensão variável, desde alguns milímetros até mais de um centímetro de diâmetro, em alguns pontos.

Em síntese, pode-se dizer que a razão $P / T$, no metamorfismo regional desse sistema, foi baixa na faixa Sergipana, muito baixa na zona axial de divergência e pouco mais alta na zona Sul Alagoana.

e) O magmatismo na zona Sul Alagoana é caracterizado pela presença de stocks graníticos e granodioríticos em diversos pontos, nos segmentos oriental (Alagoas) e norte-ocidental (Bahia). Há presença de diversos diques pegmatíticos e extensiva migmatização, esta em especial na periferia do batólito de Santana do Ipanema.

Na faixa Sergipana, é constatada a presença de stocks de gabro de natureza toleítica, na porção ocidental (Bahia), de dimensões modestas e de formas alongadas, segundo a foliação regional NW-SE. Camadas de metavulcânicas e piroclásticas intercaladas com os metassedimentos ocorrem esporadicamente, tendo algumas sido alvo de destaque por Humphrey e Allard (1969) na "Formação Capitão".

f) Uma fase tectônica tardia merece destaque na apreciação do Sistema de Dobramentos Sergipano. Trata-se da fase de deslocamentos gerais de norte para o sul, posterior à fase principal da tectogênese primária. Essa dinâmica impeliu o batólito de Santana de Ipanema sobre os metamorfitos da faixa Sul Alagoana, promovendo extensa cinta cataclástica e mesmo redobramento. Associam-se a esse tectonismo tardio falhas inversas e de empurrão (ao sul de Macururé, Formosa, norte de Bendegó) e clivagem de fratura que interceptam os metamorfitos de ambas as faixas.

$\mathrm{Na}$ faixa Sergipana, os metassedimentos acham-se empurrados sobre os sedimentos da antefossa (Grupo Estância), em trechos de observação não-contínua. Esses fatores sugerem que essa dinâmica de empurrões tenha se situado já no Fanerozóico (pós-ordovicianos?), levando-se em consideração a idade ordoviciana (470 \pm 15 m.a.) atribuída recentemente ao Estância (Brito Neves e Kawashita, em preparação).

g) Do ponto de vista do levantamento pós-tectogenético (no Fanerozóico), há indicações seguras de efeitos mais pronunciados na faixa Alagoana. É verificado um maior arrasamento erosional, permitindo a freqüente exposição dos núcleos anticlinoriais, progradação de chãs e de depósitos correlativos. A ausência de depósitos molássicos pode ser 
creditada em parte à atividade erosiva, que em toda faixa Sul Alagoana é empecilho para a reconstituição completa da seqüência estratigráfica.

Na faixa Sergipana, a dissecação erosiva não foi tão acentuada, havendo maior preservação das unidades litoestratigráficas e um arrasamento em escala menor. As estruturas, apesar de rebaixadas, ainda influenciam de forma decisiva a morfologia, conforme se pode atestar na expressão morfológica do anticlinório de Pinhão, com o calcário Olhos d'Água em relevo.

As bacias (semigrábens) mesozóicas de Alagoas-Sergipe mostram diferenças notórias entre as frações situadas sobre a projeção de uma e de outra zona de dobramentos. Por exemplo, em Alagoas há preservação apenas do Grupo Baixo São Francisco e da Formação Muribeca, faltando o Grupo Sergipe. Em Sergipe, a preservação é melhor, destacando-se a preservação do Grupo Sergipe, que representa o "intervalo marinho franco" neocretácico/terciário (veja Schaller, 1969), final do desenvolvimento.

Zona axial de divergência A zona axial de divergência do Sistema de Dobramentos Sergipano situa-se ao longo do paralelo de Propriá, sendo concebida como uma zona linear de dobramentos com características típicas de uma evolução geoanticlinal.

Situada entre duas distintas e simétricas zonas de dobramentos (Sul Alagoana e Sergipana), é perlongada por freqüentes exposições do embasamento do sistema e numerosos stocks de caráter calco-alcalino. Mostra, assim, evidências de ter abrigado, em seu dorso, uma pilha sedimentar de menor espessura que as zonas vizinhas e uma tendência a movimentos ascensionais positivos desde o processo de instalação do desenvolvimento. Evidências adicionais desse comportamento são encontradas no estilo do dobramento (menor encurtamento crustal relativo) e no tipo de metamorfismo desenvolvido (predomínio da temperatura sobre a pressão), como anteriormente discutido.

O embasamento do sistema acha-se exposto em diversas localidades ao longo dessa zona, como em Igreja Nova, Propriá, Monte Alegre de Sergipe, Pedro Alexandre, imediações da intrafossa de Juá, ao norte de Canudos (BA), com evidências de posição subaflorante em outras áreas.

A seqüência calco-alcalina está marcada pela presença de stocks de biotita granodiorito (Muribeca, Propriá, Itabi, Glória, Garira, Cel. João Sá, ao sul de Formosa) e quartzo-monzonitos pobres em máficos, relativamente bem alinhados, que consubstanciam a formação de hornfelses, que foram suficientemente descritos por Humphrey e Allard, 1969.

As rochas situadas ao longo desse alinhamento de stocks calco-alcalinos acham-se arqueadas e o grau de deformação é comparativamente menor que os das faixas Sul Alagoana e Sergipana. O acamadamento das unidades litológicas reaparece, com suaves mergulhos, com sensível arrefecimento da foliação, em geral.

Nas diferentes etapas da evolução dessa zona de dobramentos intermediária, estão patentes registros de movimentos verticais positivos, como a partir do processo de sua diferenciação no sistema.

A presença de wild flysch, identificado ao norte de Gracho Cardoso, em Sergipe, no flanco dessa zona axial, demonstra seu caráter de alto estrutural emergente (Aubouin, 1965; Hsu, 1974), ao longo do processo de sedimentação. Trata-se de uma unidade litológica caracterizada pela presença de blocos de filitos grafitosos, ardósias, boulders graníticos e fragmentos de rochas do embasamento (gnaisses, migmatitos, pegmatitos), com dimensões de centímetros até um metro. Há praticamente ausência de matriz em certos trechos do depósito, reconhecendo-se distintos pacotes (de 2 a $3 \mathrm{~m}$ de espessura) separados entre si por bancos (de 0,5 a $1 \mathrm{~m}$ de espessura) de material arcosiano, de forma 
que se pode esperar certa ritmicidade no evento de sedimentação. Provavelmente a deposição desse material foi tardia, envolvendo remoção e redeposição de rochas, uma vez que, nos blocos de ardósia nele contidas, verificam-se microdobramentos de fluxo e mesmo veios de quartzo a recortá-las.

Outra evidência da movimentação vertical, nessa zona axial do sistema, é a presença da intrafossa de Juá-Fazenda de Dentro, típica do desenvolvimento de horsts e grábens interiores, com deposição, nos grábens, de sedimentos imaturos, variegados, incluindo blocos do embasamento e dos metamorfitos. $\mathrm{E}$ ainda, trapeamento estrutural, em gráben, de rochas do Grupo Brotas (jurássico superior) mostrando a persistência dos movimentos de blocos, ao longo das mesmas linhas de falhas, em etapas paraplataformais bastante distanciadas, no tempo, da fase tectogenética tardia.

Por outro lado, a projeção para oeste dessa zona axial, reativada ao longo do Fanerozóico, causou estrangulamento importante, do ponto de vista estrutural, com repercussões litoestratigráficas, na Bacia de Tucano, correspondendo ao chamado "arco do Vaza Barris" (que separa as "Bacias" de Tucano Centro de Tucano Norte).

A designação de "zona axial de divergência" adotada procura dar ênfase à interessante distribuição centrífuga das vergências das zonas de dobramentos separadas por essa dorsal e atender a uma nomenclatura preexistente, de uso e aceitação suficientemente amplas (Aubouin, 1965).

Hipótese de evolução tectônica Qualquer modelo de evolução tectônica proposto para sistemas de dobramentos pré-cambrianos encontrará rígidas limitações e defrontará riscos inerentes à falta de registros geológicos completos, entre outros. Os modelos a que se pode recorrer em geral se fundamentam em desenvolvimentos geotectônicos estudados a um nível de maior prófundidade, na maior parte do Fanerozóico, e todos eles submetidos, de forma inevitável e subjetiva, a uma tradição de linha de pensamento.

Em cada nova unidade geotectônica que se estuda, persistem/aparecem peculiaridades que escapam ao rigor dos modelos de desenvolvimento de mais ampla circulação. Embora se reconheçam linhas gerais e ecléticas de organização e evolução, não se pode esperar desenvolvimentos geotectônicos em padrões, nem se deve partir, em cada nova unidade, para a formulação de novos modelos, ou para modelos excepcionais.

Na apreciação geotectônica do Sistema de Dobramentos Sergipano, são reconhecidos as limitações, os riscos e os problemas acima mencionados. Um aprimoramento progressivo do conhecimento geotectônico regional é necessário e será conduzido.

Ao longo deste trabalho, foi utilizada a nomenclatura geossinclinal clássica (euro-asiática) para nomear os diferentes elementos da organização geotectônica em análise, o que deve ser compreendido por razões eminentemente descritivas.

A aplicação e o ajustamento do modelo clássico de par elementar ou de bi-pares divergentes incompletos, de Aubouin (1965), para o Sistema de Dobramentos Sergipano é viável. E isso tem sido feito por vários autores, como, por exemplo, Santos e Silva Filho (1975), recaindo em uma série de problemas, como a ausência de ofiolitos, a polaridade tectônica centrífuga, etc., em geral contornados de forma insatisfatória.

Ainda assim, essas comparações elogiáveis, com inerentes restrições, têm apenas caráter descritivo, não formulando hipóteses sobre as causas do desenvolvimento.

Muitos autores, modernamente, advogam/discutem a possibilidade do regime de placas tectônicas para explicar "orogenias" no pré-cambriano, como fizeram Engel e Kelm (1972), Hurley (1972), Piper et al.(1973), Ghesworth (1973), Burke e Dewey (1973), Katz (1974), Dewey e Spall (1975), entre muitos outros, fundamentados em dados geofísicos e geotectônicos bastante animadores. 
De acordo com essa corrente de idéias, a evolução tectônica do Sistema Sergipano poderia ser explicada, como hipótese de trabalho a ser testada, pelo choque de duas placas litosféricas rígidas, correspondentes ao Gráton do São Francisco (ao sul) e ao Maciço Pernambuco-Alagoas (ao norte). Há algumas evidências favoráveis a essa interpretação, aqui postulada, e que serão intensivamente exploradas na continuação dos levantamentos.

Os sedimentos que compunham a faixa Sul Alagoana, provavelmente mais antigos que seus pares sergipanos, foram gradativamente comprimidos, quando a "placa Pernambuco-Alagoas" se chocava com a "placa Cráton do São Francisco" (Fig. 3), após ter sido consumida segundo uma zona" de subducção mergulhando para o sul.

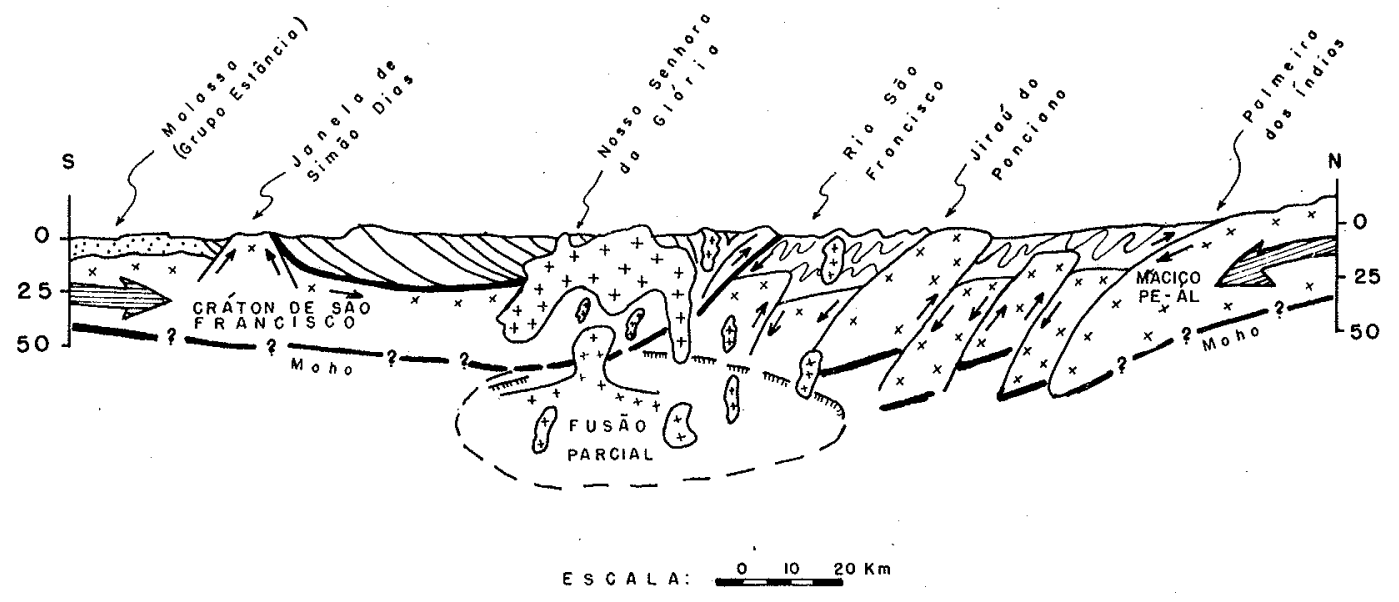

Figura 3 - Corte esquemático de Palmeira dos Indios-Alagoas a Simão Dias-Sergipe, mostrando um possivel esquema de colisão de placas litosféricas

Há possibilidade do Gráton do São Francisco ter permanecido estático, enquanto o Maciço Pernambuco-Alagoas rotacionava no sentido horário, tendo como pólo de rotação a área compreendida a noroeste de Santa Maria da Boa Vista, em Pernambuco. Essa suposição baseia-se no comportamento estrutural das lineações regionais que, naquela área, mudam bruscamente da direção N-S (advindas do cráton) para a direção NW-SW (adentrando o maciço).

Isso acontecendo, o prisma sedimentar, localizado entre essas duas "placas" foi gradativa e diferencialmente comprimido, enquanto a "placa Pernambuco-Alagoas" descia lentamente por baixo da "placa Cráton do São Francisco". Durante essa fase em que a "placa Pernambuco-Alagoas" estava sendo consumida, desenvolveram-se várias falhas sintéticas (synthetic faults, Spencer, 1969) que permitiram a subida de fatias da mesma, como em Jiraú do Ponciano, Arapiraca e Igreja Nova. Enquanto isso, a "placa Pernambuco-Alagoas" se fundiu parcialmente, possibilitando a formação anatética de magma intermediário a ácido, que intrudiu e permeou a região ao longo da zona axial de divergência, gerando granodioritos, quartzo-monzonitos e granitos.

A migmatização regional foi intensa nessa fase, com a migração de fluidos resultantes da fusão parcial de crosta siálica. Sendo o potássio elemento que se volatiliza com facilidade, uma intensa potassificação se deu nessa zona axial, fato esse evidenciado pela presença de cristais de álcali-feldspato, irregularmente distribuídos em roof pendants e mesmo em rochas básicas (como em Propriá) e nos corpos graníticos (ao sul de Poço Redondo). 
Os xenólitos encontrados nos corpos ígneos da zona axial de divergência em parte foram originados pelo alçamento, quebramento do bordo do Cráton do São Francisco e absorção dos mesmos pelo magma ascendente. Ainda devido a seu comportamento rígido, essa placa correspondente ao Cráton do São Francisco sofreu intenso fraturamento e algumas das suas porções mais superficiais sob compressão sofreram ascenção, dando origem ao Domo de Itabaiana e à Janela de Simão Dias. No período final dessa "orogênese" de colisão, a massa granítico-granodiorítica do batólito de Santana do Ipanema-Monteirópolis cavalgou os metamorfitos da faixa Sul Alagoana que sofreu, então, forte encurtamento, sem, entretanto, mascarar os granitos-granodioritos da zona axial de divergência. $O$ único local onde a polaridade centrífuga pode ainda ser observada é na porção do sistema compreendido entre Palmeira dos Índios, em Alagoas, e Simão Dias, em Sergipe (segmento oriental).

Ofiolitos sensu strictu, no moderno conceito dos drifters de pedaços de crosta oceânica, bem como xistos azuis, não foram identificados na área em estudo, até o presente momento. As rochas ultrabásicas de Batalha, Saúde, Campestre (Farina, 1966), em Alagoas, desde que estão associados com calcários e dolomitos, são provavelmente metassedimentos.

Levando-se em consideração a ausência de xistos azuis, e verdadeiros ofiolitos e que curvas de migração aparente de pólos (apparent polar wandering) não foram determinadas, o presente modelo é apenas conjectural.

Agradecimentos Os autores desejam expressar sua gratidão ao Conselho Nacional do Desenvolvimento Científico e Tecnológico (GNPq), pelo auxílio financeiro para a execução do programa de pesquisas do qual a área em estudo faz parte. Ainda aos colegas Edilton Santos e Marinho Silva Filho, pelas objetivas discussões promovidas.

\section{BIBLIOGRAFIA}

ALLARD, G. O. - 1969 - The Propriá Geosyncline, a key tectonic element in the continental drift puzzle of the South Atlantic. Anais do XXIII Congresso Bras. Geol., Salvador: 47-59

ALLARD, G. O. e TIBANA, P. - 1966 - Extensão Pré-Gretácica e Petrologia da Série Estância, reconstruída pelo estudos dos conglomerados cretáceos do Recôncavo. Bol. Téc. da Petrobrás, Rio de Janeiro (1): 17-45

ALMEIDA, F. F. M. de - 1967 - Origem e Evolução da Plataforma Brasileira. Bol. 241 do DGM/DNPM, Rio de Janeiro: $36 \mathrm{p}$.

ALMEIDA, F. F. M. de; HASUI, Y. e BRITO NEVES, B. B. - 1976 - The Upper Precambrian of South America. Bol. IG. Instituto Geocièncias, USP., 7: 45-80, São Paulo

AUbOUIN, J. - 1965 - Geosynclines. Elsevier Publishing Go., 335 p., Amsterdam

BARBOSA, O. - 1970 - Geologia Econômica de Parte da Região do Médio São Francisco. Bol. n. ${ }^{\circ} 140$, do DFPM/DNPM, Rio de Janeiro: 98 p. (Rel. inédito, Projeto Cobre, Recife/SUDENE, 1964)

BRITO NEVES, B. B. - 1975 - Regionalização Geotectônica do Pré-Cambriano Nordestino. Tese de Doutoramento, Univ. São Paulo: 198 p.

BRITO NEVES, B. B. e CORDANI, U. G. - 1973 - Problemas Geocronológicos de "Geossinclinal Sergipano" e do seu Embasamento. Anais do XXVII Cong. Bras. Geol., 2: 67-76. Aracajú (SE)

BRITO NEVES, B. B. - 1977 - Ensaio sobre a evolução litoestratigráfica do Pré-Cambriano Superior do Nordeste. Jornal do Clube de Mineralogia, 7, ed. esp., Brasília D. F. (no prelo)

BURKE, K. e DEWEY, J. F. - 1973 - An Outline of Precambrian Plate Development, in Tarling, D. H. and Runcorn, S. K. - Implications of Continental Drift to the Earth Sciences, 2: 1 035$-1045$

GAROZZI, A.V.; ARAÚJO, M. B.; CESERO, P.; FONSEGA, J. R. e LAMAS DA SILVA, V. J. - 1976 - Formação Salvador: Um Modelo de Deposição Gravitacional Subaquosa. Bol. Téc. Petrobrás, 19, n. ${ }^{\circ}$ 2, pp. 47-49 
GHESWORTH, K. G. - 1973 - Possible Plate Contact in the Precambrian of Eastern Canada. Nature Phy. Sci., 237, maio, pp. 11-12

DEWEY, J. e SPALL, H. - 1975 - Premesozoic Plate Tectonics: How far back in Earth History can Wilson Cycle be Extended? Penrose Conference Report, Geology, 3, n. ${ }^{\circ}$ 8, agosto, pp. $422-424$

ENGEL, A. E. J. e KELM, D. L. - 1972 - Prepermian Global Tectonics, A Tectonic Test. Geol. Soc. Am. Bull., 83, pp. $2325-2340$

FARINA, M. - 1966 - Asbesto de Alagoas - Relações Litológicas, Estruturais e Genéticas Importância Econômica. SUDENE/Div. Geol., B., Recife, Série Esp., 67 p.

HSU, K. J. - 1974 - Melanges and there distinction from olitostromes. Soc. Econ. Paleont. and Min. Ep. Publ., 19, pp. 321-333

HUMPHREY, F. L. e ALLARD, G. O. - 1969 - Geologia da Área do Domo de Itabaiana (Sergipe) - Um Elemento Recém-Conhecido no Escudo Brasileiro. Rio de Janeiro, Petrobrás, 157 p.

HURLEY, P. M. - 1972 - Can the Subduction Process of Mountain Building be Extended to Pan African and Similar Orogenic Belts? - Earth and Plan. Sciences Letters, 15, pp. 305-314

JORDAN, H. - 1972 - Die Mines - Gruppe in Nordest Bahia, Brasilien. Geol ${ }^{c}$ Rundschau, Stuttgart, 61(2): 441-469

JORDAN, H. - 1971 - The Late Precambrian Synclinorium of Curaçá (Brazil). Geol. Jahrbuch, Hannover (88): 617-628

KATZ, M. B. - 1974 - Paired Metamorphic Belts in Precambrian Granulites Rocks in Gondwanaland. Geology, maio, pp. 237-241

KEGEL, W. e BARROSO, J.A. - 1966 - Contribuições à Geologia do Submédio e Baixo Rio São Francisco. DNPM/DGM, Bol. 231, Rio de Janeiro: 42 p.

KHAIN, V. Ye e SHEYNMANN, Yu. M. - 1962 - Hundredth Anniversary of the Geosynclinal Theory. Int. Geol. Rev., 4(2): 166-197

LEAL, A. S. - 1970 - Inventário Hidrogeológico do Nordeste, Folha 19, Aracaju-NO. Brasil/SUDENE, Série Hidrogeologia, n. ${ }^{\circ} 33$, Recife: 242 p.

LEITE, W. A. - 1969 - Geologia do Baixo São Francisco e Depósitos de Asbesto em Alagoas. Recife, SUDENE/Div. Geol: 77 p.

PIPER, J. D. A.; BRIDEN, J. C. e LOMAX, K. - 1973 - Precambrian Africa and South America as a single Continent. Nature, 245, pp. 244-248

SANTOS, E.J. dos e SILVA FILHO, M. A. - 1975 - Ensaio Interpretativo sobre a Evolução da Geossinclinal de Propriá, Nordeste do Brasil. Miner. Met., Ano XXXIX, n. ${ }^{\circ} 367$, outubro, pp. $3-22$

SCHALLER, H. - 1969 - Revisão Estratigráfica da Bacia Sergipe-Alagoas. Bol. Téc. Petrobrás, 12, n. ${ }^{\circ}$ 1, pp. $21-86$

SPENCER, E. W. - 1969 - Introduction to the Structure of the Earth. McGraw Hill Book Co., 597 p., New York

SOBRAL, J. F. - 1964 - Geologia da Área entre as Bacias do Recôncavo, Tucano e Sergipe. Setor de Exploração/Petrobrás/SERDESTE, Rel. 289, Maceió (Circul. Restrita)

ZONENSHAYN, L. P. - 1967 - Tectonic of the Folded Regions of Central Asia (The Structural Patterns of Geosynclinal Regions). Geotectonics (6): pp. 356-365

Referência especial para o mapa

COMISSION DE LA GARTE GEOLOGIQUE DU MONDE, SOUS COMISSION DE LA CARTE TECTONIQUE, 1971. Legende pour la Carte Tectonique International au $1: 2.500 .000$, 2. ${ }^{\mathrm{a}}$ ed., 20 p., Moscou 